\title{
Platelet Recruitment during Multiple Donor Platelet Apheresis Differs between Cell Separators
}

\author{
Stefano Fontana ${ }^{\mathrm{a}}$ Peter Keller ${ }^{\mathrm{b}} \quad$ Behrouz Mansouri Taleghani $^{\mathrm{b}}$ \\ a Blood Transfusion Service of the Swiss Red Cross, \\ ${ }^{\mathrm{b}}$ Department of Hematology and Central Hematology Laboratory, Division of Transfusion Medicine, Inselspital, \\ University Hospital, Bern, Switzerland
}

\section{Keywords}

Platelet apheresis - Platelet recruitment .

Cell separator

\section{Summary}

Background: Recruitment of platelets (PLT) during donor PLT apheresis may facilitate the harvest of multiple units within a single donation. Methods: We compared two PLT apheresis procedures (Amicus and Trima Accel) in a prospective, randomized, paired cross-over study in 60 donors. The 120 donations were compared for depletion of circulating PLT in the donors, PLT yields and PLT recruitment. A recruitment was defined as ratio of total PLT yield and donor PLT depletion > 1. Results: Despite comparable differences of pre- and post-apheresis PLT counts $\left(87 \times 10^{9} / \mathrm{I}\right.$ in Trima Accel vs. $92 \times 10^{9} / \mathrm{I}$ in Amicus, $\mathrm{p}=0.383), \mathrm{PLT}$ yields were higher with Trima Accel $\left(7.48 \times 10^{11}\right.$ vs. $\left.6.06 \times 10^{11}, \mathrm{p}<0.001\right)$, corresponding to a higher PLT recruitment (1.90 vs. $1.42, \mathrm{p}<0.001)$. We observed a different increase of WBC counts after aphereses, which was more pronounced with Trima Accel than with Amicus $\left(1.30 \times 10^{9} / \mathrm{l}\right.$ vs. $0.46 \times 10^{9} / \mathrm{l}, \mathrm{p}<$ 0.001). Conclusion: Both procedures induced PLT recruitment. This was higher in Trima Accel, contributing to a higher yield in spite of a comparable depletion of circulating PLT in the donors. This recruitment facilitates the harvest of multiple units within a single donation and seems to be influenced by the procedure utilized. The different increases of circulating donor white blood cells after donation need further investigation.

\section{Schlüsselwörter \\ Thrombozytapherese - Thrombozytenrekrutierung · Zellseparator}

\section{Zusammenfassung}

Hintergrund: Die Rekrutierung von Thrombozyten während der präparativen Thrombozytapherese könnte die Gewinnung von mehreren Produkten aus einer einzelnen Spende unterstützen. Methoden: Wir verglichen zwei Apheresemethoden (Amicus und Trima Accel) in einer prospektiven, randomisierten, gepaarten Studie mit Crossover in 60 Spendern. In den 120 Spenden wurden Thrombozytendepletion beim Spender sowie Ertrag und Rekrutierung von Thrombozyten verglichen. Eine Rekrutierung wurde als Verhältnis Thrombozytenertrag zu Thrombozytendepletion beim Spender > 1 definiert. Ergebnisse: Trotz vergleichbarer Unterschiede in der Thrombozytenzahl vor und nach Apherese $\left(87 \times 10^{9} / \mathrm{l}\right.$ mit Trima Accel vs. $92 \times 10^{9} / \mathrm{l}$ mit Amicus, $\mathrm{p}=0,383$ ) waren Thrombozytenertrag $\left(7,48 \times 10^{11}\right.$ vs. $\left.6,06 \times 10^{11}, p<0,001\right)$ und Thrombozytenrekrutierung (1,90 vs. $1,42, p<0,001)$ höher mit Trima Accel. Wir beobachteten einen unterschiedlichen Anstieg der Leukozytenzahl nach Apherese, der ausgeprägter mit Trima Accel als mit Amicus war $\left(1,30 \times 10^{9} / \mathrm{l}\right.$ vs. $\left.0,46 \times 10^{9} / \mathrm{l}, \mathrm{p}<0,001\right)$. Schlussfolgerung: Beide Verfahren lösten eine Rekrutierung von Thrombozyten aus, die mit Trima Accel ausgeprägter war und einen höheren Ertrag an Thrombozyten lieferte - trotz vergleichbarer Plättchendepletion der Spender. Diese Rekrutierung unterstützt die Gewinnung von mehreren Einheiten aus einer einzelnen Spende und scheint vom eingesetzten Verfahren abhängig zu sein. Der unterschiedliche Anstieg der Leukozyten der Spender muss weiter untersucht werden.

\section{KARGER}

Fax +497614520714

Information@Karger.de

www.karger.com (c) 2011 S. Karger GmbH, Freiburg

Accessible online at:

www.karger.com/tmh 


\section{Introduction}

In recent years, the use of platelet (PLT) concentrates obtained from single donors by automated apheresis has grown steadily. Their increasing availability provides an efficient PLT replacement while minimizing patient exposure to multiple donors [1].

Different technologies have been developed with the aim to improve efficiency and tolerance of PLT collection. The newest generation of cell separators is characterized by high PLT yields as a precondition for the production of multiple PLT concentrates from a single donation [2-4]. The donation-induced depletion of the donor's circulating PLT count represents one of the main safety limits for the production of multiple PLT concentrates. Recruitment of PLT during donor PLT apheresis may prevent post-procedure thrombocytopenia, thereby increasing the safely achievable maximal PLT yield.

\section{Material and Methods}

In a previously reported prospective, randomized, paired cross-over study [4] donors were randomly assigned to platelet apheresis via Amicus (A) Version 2.51 (Fenwal Deutschland GmbH, Munich, Germany), (n=30) or via Trima Accel (T) Version 5 (Caridian BCT Europe, Garching, Germany) $(\mathrm{n}=30)$ and changed to the other cell separator for the $2 \mathrm{nd}$ donation 4-8 weeks later. All donors gave written informed consent before inclusion in the study. Approval by the local ethical committee was obtained.

Table 1. Basic donor characteristics and donor blood counts*
Detailed information about methods and PLT donations are reported elsewhere [4]. Briefly, the duration of donations was individually tailored to obtain the highest possible number of units containing at least $2 \times 10^{11}$ PLTs within a maximal apheresis duration of $100 \mathrm{~min}$. At the beginning of the donation the setting was based on the PLT count and hematocrit (HCT) level of the previous donation. 15-20 min later it was adjusted regarding the current pre-collection analyses. For procedures using $\mathrm{A}$ we adjusted to a standard anticoagulant (AC) ratio of 10 , a citrate infusion rate of $1.25 \mathrm{mg} / \mathrm{kg} / \mathrm{min}$ and a maximal cycle volume of $200 \mathrm{ml}$. The settings for the $\mathrm{T}$ procedures included an $\mathrm{AC}$ ratio of 12, an $\mathrm{AC}$ infusion rate level of 5, a maximal draw flow of 'high', a draw flow of 6 and a return flow of 3 .

The $2 \times 60$ donations of the before mentioned study [4] were further compared for different variables, including pre- and post-apheresis PLT and white blood cell (WBC) counts, mean PLT volume (MPV), HCT, $\mathrm{PLT}$ yield/h (= collection rate; CR), and PLT yield per processed blood volume of the donor (relative efficiency; RE). We measured the MPV before and after apheresis in order to find out if a release of younger PLT (typically with a higher MPV) in the circulating blood occurs, being consistent with a PLT recruitment from an extravascular site. The PLT recruitment was defined as the ratio of the total PLT yield and the depletion of circulating PLT in the donor:

Recruitment $=$ PLT yield $/\left(\mathrm{PLT}_{\text {before }}-\mathrm{PLT}_{\text {after }}\right) \times$ donor blood volume

A recruitment was assumed if the ratio was $>1$. Its correlation with donor and donation variables was separately analyzed for $\mathrm{A}$ and $\mathrm{T}$ donations.

\section{Statistical Analysis}

All data were analyzed with computer software (NCSS, Kaysville, UT, USA). Donor and donation data were compared using the $t$ test for paired samples (parametric data) and the Wilcoxon signed-rank test for nonparametric data. The presence of a statistically significant recruitment was assumed if the lower threshold of its $95 \%$ confidence interval $(95 \%$ CI) was $>1$.

\begin{tabular}{|c|c|c|c|}
\hline & Donors & & $\mathrm{p}$ value \\
\hline Number & 59 & & - \\
\hline Height, cm & $176(174-178)$ & & - \\
\hline Weight, kg & $77(74-81)$ & & - \\
\hline Blood volume, $\mathrm{ml}$ & $5,013(4,829-5,198)$ & & - \\
\hline \multirow[t]{2}{*}{$\operatorname{Sex}(M / F)$} & $49 / 10$ & & - \\
\hline & Amicus & Trima Accel & $\mathrm{p}$ value \\
\hline \multicolumn{4}{|l|}{ Platelet count $\left(\times 10^{9} / 1\right)$} \\
\hline Before apheresis & $262(249-275)$ & $260(247-272)$ & 0.553 \\
\hline After apheresis & $170(163-178)$ & $172(165-179)$ & 0.731 \\
\hline Difference & $92(84-99)$ & 87 (79-96) & 0.383 \\
\hline \multicolumn{4}{|c|}{ Leukocyte count $\left(\times 10^{9} / 1\right)$} \\
\hline Before apheresis & $5.85(5.45-6.25)$ & $5.81(5.41-6.20)$ & 0.771 \\
\hline After apheresis & $6.30(5.87-6.74)$ & $7.11(6.57-7.65)$ & $<0.001$ \\
\hline Difference & $0.46(0.29-0.62)$ & $1.30(0.92-1.68)$ & $<0.001$ \\
\hline \multicolumn{4}{|l|}{ Hematocrit, \% } \\
\hline Before apheresis & $42.8(41.9-43.7)$ & $42.7(41.9-43.6)$ & 0.482 \\
\hline After apheresis & $42.2(41.2-43.2)$ & $42.7(41.9-43.5)$ & 0.105 \\
\hline Difference & $-0.6(-1.0$ to -0.2$)$ & $0.0(-0.3-0.3)$ & 0.025 \\
\hline \multicolumn{4}{|l|}{ MPV, fl } \\
\hline Before apheresis & $7.58(7.39-7.76)$ & $7.56(7.38-7.73)$ & 0.629 \\
\hline After apheresis & $7.94(7.73-8.16)$ & $7.86(7.65-8.07)$ & 0.149 \\
\hline Difference & $0.36(0.29-0.46)$ & $0.30(0.20-0.41)$ & 0.288 \\
\hline
\end{tabular}




\begin{tabular}{lllr}
\hline & Amicus & Trima Accel & p value \\
\hline Total donation number & 59 & 59 & - \\
Duration, min & $89(88-90)$ & $79(76-82)$ & $<0.001$ \\
ACD-A used, ml & $489(479-499)$ & $469(449-489)$ & 0.039 \\
Processed blood volume, $\mathrm{ml}^{* *}$ & $3,963(3,841-4,085)$ & $4,331(4,148-4,514)$ & $<0.001$ \\
Obtained PLT yield $\left(\times 10^{11}\right)$ & $6.06(5.65-6.47)$ & $7.48(6.95-8.01)$ & $<0.001$ \\
\hline *Data are reported as mean $(95 \%$ CI of the mean). & & \\
**Corrected for ACD-A. & & & \\
\hline
\end{tabular}

Table 3. Collection efficiency and PLT recruitment*

\begin{tabular}{llll}
\hline & Amicus & Trima Accel & p value \\
\hline CR $\left(\times 10^{11} / \mathrm{h}\right)$ & $4.10(3.81-4.38)$ & $5.68(5.33-6.03)$ & $<0.001$ \\
Processed blood volume / donor blood volume & $0.80(0.78-0.82)$ & $0.87(0.84-0.90)$ & $<0.001$ \\
RE & $0.59(0.56-0.62)$ & $0.66(0.64-0.69)$ & $<0.001$ \\
PLT yield / total donor PLT & $0.47(0.44-0.50)$ & $0.57(0.55-0.60)$ & $<0.001$ \\
Recruitment (PLT reduction / PLT yield) & $1.42(1.30-1.54)$ & $1.90(1.65-2.14)$ & $<0.001$ \\
\hline *Data are reported as mean (95\% CI of the mean). & & \\
\hline
\end{tabular}

\section{Results}

59 of the 60 enrolled donors completed the study. All resulting 118 donations were evaluable and yielded PLT concentrates meeting current Swiss quality standards. One donor was excluded because moving abroad before the second donation.

The basic characteristics of the donors and the laboratory values before and after PLT collection are summarized in table 1. Although the PLT counts before and after donation and the difference of pre- and post-apheresis PLT counts were comparable for $\mathrm{T}$ and $\mathrm{A}$, the PLT yield was higher for $\mathrm{T}$, in spite of a shorter apheresis duration (table 2). This corresponded to a higher collection rate and relative efficiency during apheresis with $\mathrm{T}$ (table 3). A relevant PLT recruitment (lower threshold of the $95 \% \mathrm{CI}>1$ ) was observed with both collection procedures but was significantly higher with $\mathrm{T}$ (table 3 ).

The MPVs before and after collection were comparable in the two groups. However, they differed significantly before and after PLT apheresis. In the A donations, mean MPV before was 7.59 (95\% CI 7.40-7.78) and mean MPV $_{\text {after }} 7.96$ (95\% CI 7.74-8.17; $\mathrm{p}<0.001)$. In the $\mathrm{T}$ donations mean $\mathrm{MPV}_{\text {before }}$ was $7.56\left(95 \%\right.$ CI 7.38-7.73) and mean MPV $_{\text {after }} 7.86$ (95\% CI 7.66-8.07; $\mathrm{p}<0.001)$.

During the PLT apheresis we further observed a significant increase of the donor WBCs in A and T procedures $(\mathrm{p}<0.001$ for both) (table 1). This increase differed significantly between the PLT apheresis devices and was more pronounced in $\mathrm{T}\left(1.30 \times 10^{9}\right.$ vs. $\left.0.46 \times 10^{9} / 1, \mathrm{p}<0.001\right)$.

\section{Discussion}

Renewed concerns about safety of PLT concentrates will probably further increase costs and complexity of their pro- duction and reduce the availability of donors. New safety requirements are established or in evaluation, for example bacterial testing, pathogen inactivation, or exclusion of females from donation of plasma containing components for prevention of TRALI [5, 6]. Contemporarily, the need of PLT concentrates obtained from single donors by apheresis is increasing, and with this the interest in the production of multiple PLT concentrates from a single donation.

In our previously reported study [4], the donations were individually tailored in order to obtain the highest number of standard units containing $2 \times 10^{11} \mathrm{PLT}$ within $100 \mathrm{~min}$. This acceptable duration of donations up to 100 min results in a reduction of the ratio between the initial period (adjustment of interface) and the consecutive stable collection phase and therefore in a higher CR $[3,4,7]$. However, the donationinduced decrease of the donor's circulating PLT count may represent a safety limit for the production of multiple PLT concentrates. A recruitment of PLT during apheresis may partially counterbalance the PLT extraction and thereby increase the safely achievable maximal PLT yield.

In both PLT apheresis procedures performed with A or T, the actual PLT yield exceeded significantly the calculated yield, i.e. the calculated number of circulating PLT removed from the donor's blood using the pre- and post-PLT count and the blood volume of the donor. This allowed the collection of a high proportion of multiple units per donation [4] despite a normal or slightly decreased post-apheresis PLT count (in all donors between 120 and $220 \times 10^{9} / 1$ ). However, the recruitment was significantly higher in the PLT aphereses performed with $\mathrm{T}$ than with $\mathrm{A}$. This contributed to a higher yield and hence a higher proportion of multiple donations, despite identical pre- and post-apheresis PLT counts (table 1). The donation-induced decrease of the donor's circulating PLT count, which represents one of the main safety limits for 
the production of multiple PLT concentrates, seems therefore to be markedly influenced by the device and/or procedure utilized. This should be considered in the development of specific guidelines.

In order to support the hypothesis of PLT recruitment by further empirical data, we measured the MPV of the donors before and after PLT apheresis. The increasing MPV during PLT apheresis seems to support the hypothesis of a recruitment of PLT from an extravascular site into the circulating blood with both procedures. This would support the hypothesis formulated 25 years ago that PLT are recruited from the spleen during apheresis, which in particular was based on the observation that splenectomized patients in remission from leukemia did not show such a recruitment $[8,9]$. We did not find a correlation between MPV and recruitment, and the MPV increase did not differ between the 2 procedures. But this should be interpreted with caution because this analysis was not the primary objective of the study and was performed on two small groups of donations.

Interestingly, we further observed a difference in the increase of donor WBCs between the two PLT apheresis procedures tested, being more pronounced in $\mathrm{T}$ (table 1). This may be related to a different extent of WBC sequestration in the different extra-corporal systems of the two devices. The accumulated WBCs may be flushed back to the donor at the end of the procedure to a different extent. Alternatively, there may be a different mobilization of marginal peripheral blood WBCs (for example related to a different citrate toxicity [3]) or other unknown factors. The increase of donor WBCs after donation also did not correlate with PLT recruitment and needs further investigation.
Recruitment of collected cells during apheresis is a recently reported phenomenon for peripheral blood progenitor cells [10]. Like in autologous peripheral blood progenitor cell collection, increasing the processed blood volume may be helpful to increase the yield per donation. With the already mentioned statistical limitations, the absence of a negative correlation between recruitment and parameters defining the 'magnitude' of the apheresis (e.g. duration, processed blood volume or yield) may imply that the upper limit of processed blood volume revealing a sustained recruitment still was not reached. However, a further intensification of the PLT apheresis procedure may be limited by other factors sich as side effects for donors or an impaired effectiveness of the transfused PLT [11].

In conclusion, both cell separators induced a PLT recruitment during multiple PLT apheresis. This recruitment was significantly higher in T, contributing to a higher PLT yield, $\mathrm{CR}$ and RE, in spite of a comparable post-apheresis decrease of circulating PLT counts in the donor. The post-apheresis PLT count, which represents one of the main safety limits for donors, seems therefore to be markedly influenced by the device and/or procedure utilized. Our results and previously reported differences of multiple PLT donations concerning effectiveness of the products [11] and safety of the procedures [4] should be considered in the establishment of guidelines limiting the number of yielded units per donation.

\section{Disclosure Statement}

The authors declare no conflict of interest.

\section{References}

1 Ness PM, Campbell-Lee SA: Single donor versus pooled random donor platelet concentrates. Curr Opin Hematol 2001;8:392-396.

$\checkmark 2$ Burgstaler EA, Pineda AA, Wollan P: Plateletapheresis: comparison of processing times, platelet yields, and white blood cell content with several commonly used systems. J Clin Apheresis 1997;12: 170-178.

3 Burgstaler EA, Jeffrey LW, Pineda AA: Paired comparison of Gambro Trima Accel versus Baxter Amicus single-needle plateletpheresis. Transfusion 2004;44:1612-1620.

4 Fontana S, Mordasini L, Keller P, Mansouri Taleghani B: Prospective, paired crossover comparison of multiple, single-needle plateletpheresis procedures with the Amicus and Trima Accel cell separators. Transfusion 2006;46:2004-2010.
5 Stainsby D, Jones H, Asher D, Atterbury C, Boncinelli A, Brant L, Chapman CE, Davison K, Gerrard R, Gray A, Knowles S, Love EM, Milkins C, McClelland DB, Norfolk DR, Soldan K, Taylor C, Revill J, Williamson LM, Cohen H: Serious hazards of transfusion: a decade of hemovigilance in the UK. Transfus Med Rev 2006;20:273-282.

6 Kleinmann S, Grossman B, Kopko P: A national survey of transfusion-related acute lung injury risk reduction policies for platelets and plasma in the United States. Transfusion 2010;50:1312-1321.

7 Bueno JL, García F, Castro E, Barea L, González $\mathrm{R}$ : A randomized crossover trial comparing three plateletpheresis machines. Transfusion 2005;45: 1373-1381.
8 Heyns AD, Badenhorst PN, Lötter MG, Pieters $\mathrm{H}$, Wessels P: Kinetics and mobilization from the spleen of indium-111-labeled platelets during platelet apheresis. Transfusion 1985;25:215-218.

9 Lee EJ, Schiffer CA: Evidence for rapid mobilization of platelets from the spleen during intensive plateletpheresis. Am J Hematol 1985;19:161-165.

10 Fontana S, Groebli R, Leibundgut K, Pabst T, Zwicky C, Mansouri Taleghani B: Progenitor cell recruitment during individualized high-flow, very large volume apheresis for autologous transplantation improves collection efficiency. Transfusion 2006;46:1408-1416.

11 Julmy F, Ammann RA, Mansouri Taleghani B, Fontana S, Hirt A, Leibundgut K: Effects of highyield thrombocytapheresis on the quality of platelet products. Transfusion 2008;48:442-450. 